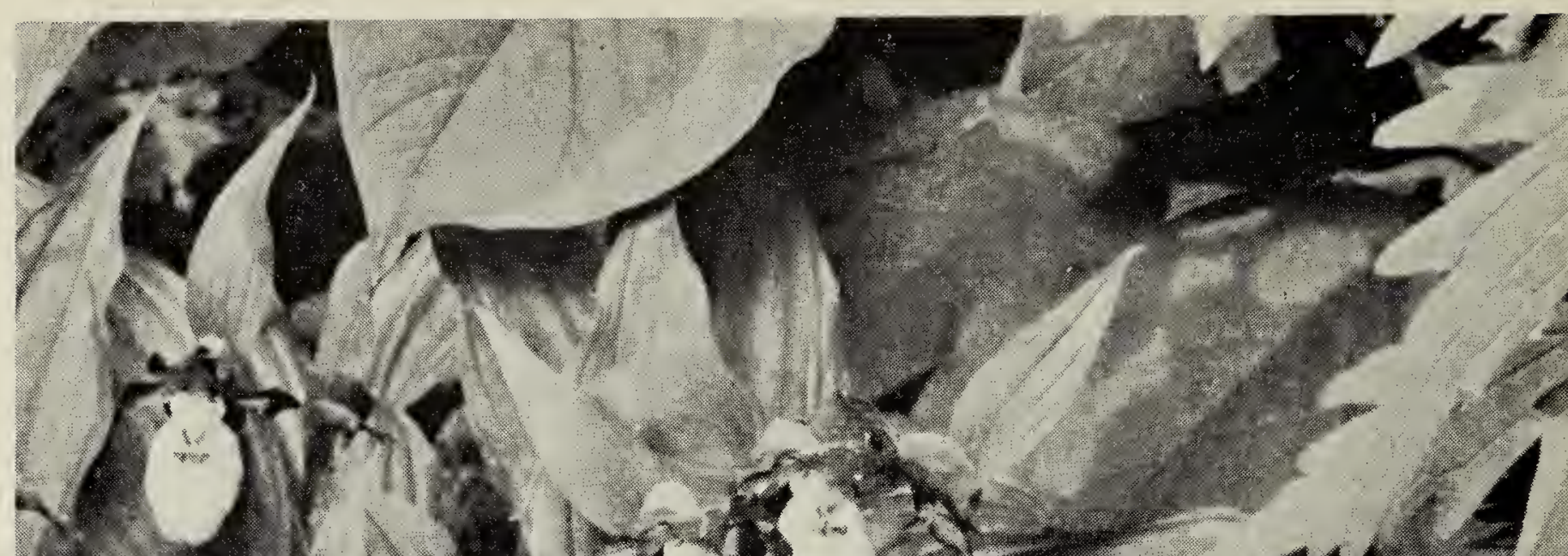
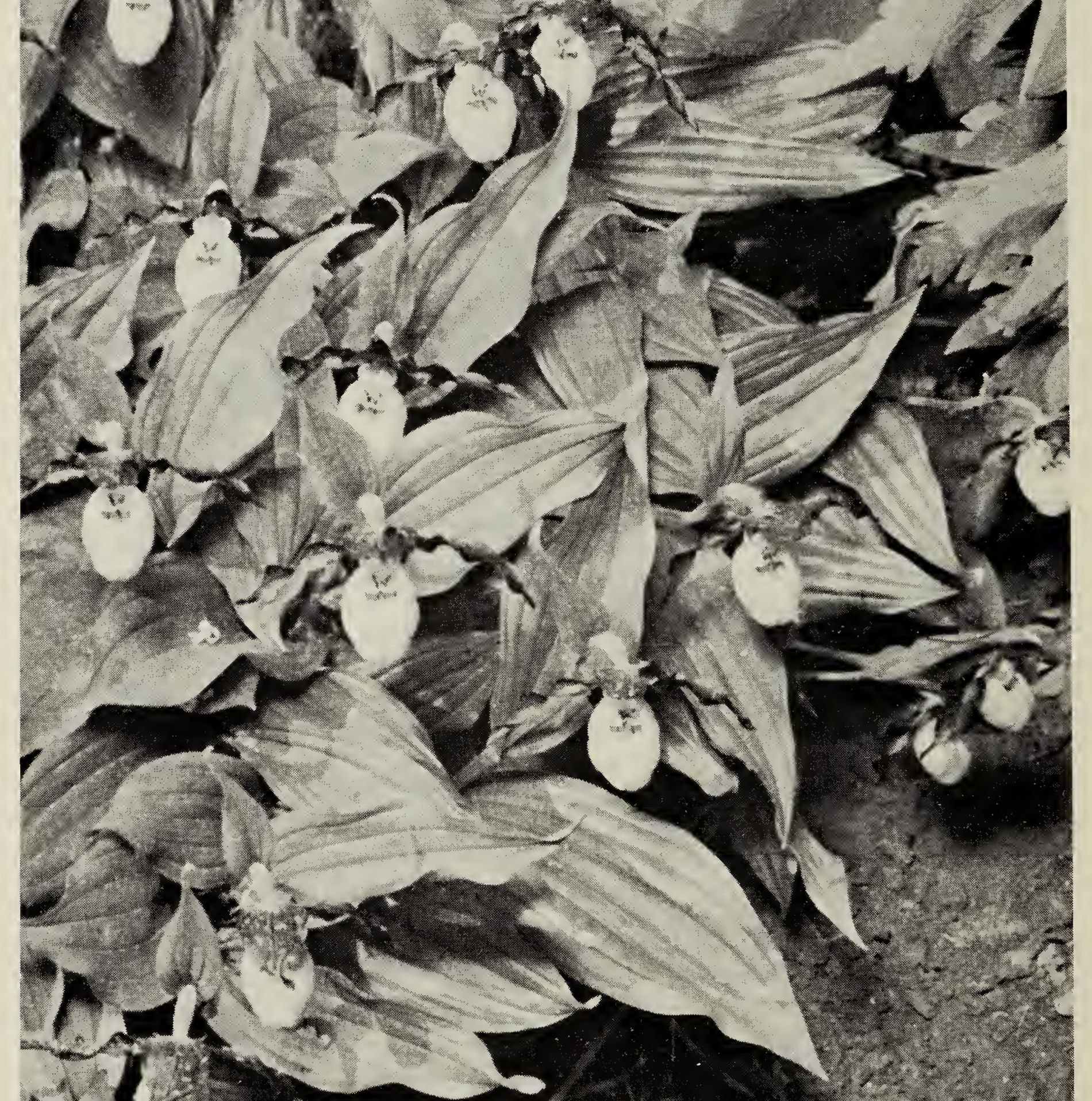

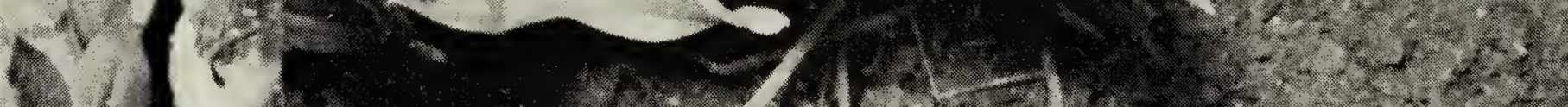

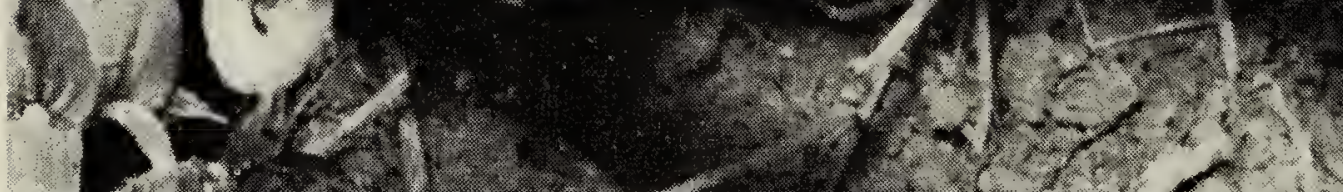

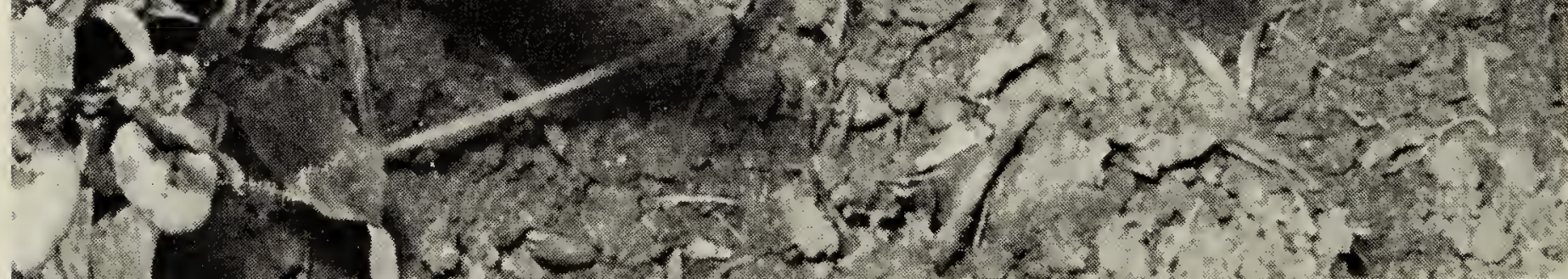

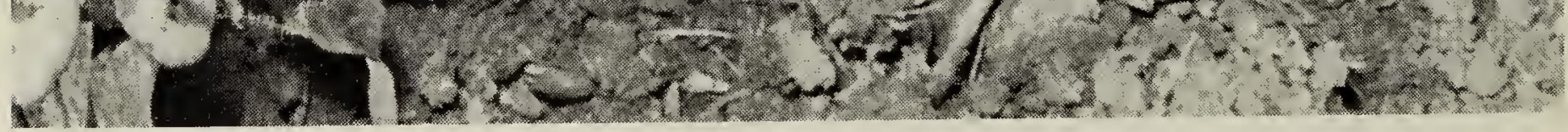

The Yellow Lady's-slipper 


\section{YELLOW LADY'S-SLIPPER}

Dr. R. W. Kirkby, 836 - 20th West, Prince Albert, sent in the accompanying photo of the Yellow Lady's-slipper and also a beautiful color photo of two flowers of this orchid on one stem. $\mathrm{He}$ found as many as 60 flowers on some plants.

Mr. J. Turnquist who sold his farm at Wallwort in 1965 moved one clump of Yellow Lady's-slipper in to Saskatoon where he had retired about ten years ago. He knew that the new owner was going to cultivate the area so he took a root and divided it and was pleased this year to see nine blooms on one of the plants.

Mrs. O. L. Wolters who has moved from Tolland to Edmonton where she works in the University hospital writes that the Yellow Lady's-slipper is still her prized possession. She obtained a plant by correspondence, from a Blue Jay member, "years ago". She has divided the plant many times. It grows in the gardens of many of her friends and last year she brought it to her rented garden in Edmonton where she has enjoyed 15 blooms in 1966. It is nice to be able to see this beautiful flower in our gardens but it is to be hoped that there will always be places in Saskatchewan where it can flourish in its natural setting.

\section{HAREBELL OR BLUEBELL} by Keith F. Best, Experimental Farm
Swift Current

The bluebells of Scotland are not restricted to the land of the deep lochs and bonnie braes. It and many close relatives are found growing throughout North America. A member of the Bluebell Family, Harebell (Campanula rotundifolia L.) is a common plant throughout the Canadian prairies. A perennial, it grows from a rootstock to a height of 4 to 18 inches, often with many stems. The early basal leaves are very different from the narrow stem leaves, being rounded, with heart-shaped bases, giving rise to the specific name of rotundifolia. They are quite evident early in the season, but soon wither and disappear by flowering time.
The flowers are blue, campanulate (bell-shaped) and are from $5 / 8$ to $3 / 4$ inch long. Sometimes found singly, but generally occur in racames of 3 to 4 flowers. The flowers have 5 united petals, 5 stamens, and 3 to 5 stigmas, while the fruit is an ovoid capsule containing many seeds.

Through time, the five once-separate petals have become fused together until the present solid bell-shaped structure resulted. This arrangement makes insect fertilization a much more certain process because none of the pollen is lost through openings between the petals, and because the visitor must enter the flower only at the vital point where the stigmas come in contact with his pollen-laden body. If cross-fertilization is not effected by the time the flower must wither, the stigmas, sticky on their under surface, bend downward and absorb whatever is left of the plant's own pollen at the base of the flower, thus insuring the production of seed by self-fertilization.

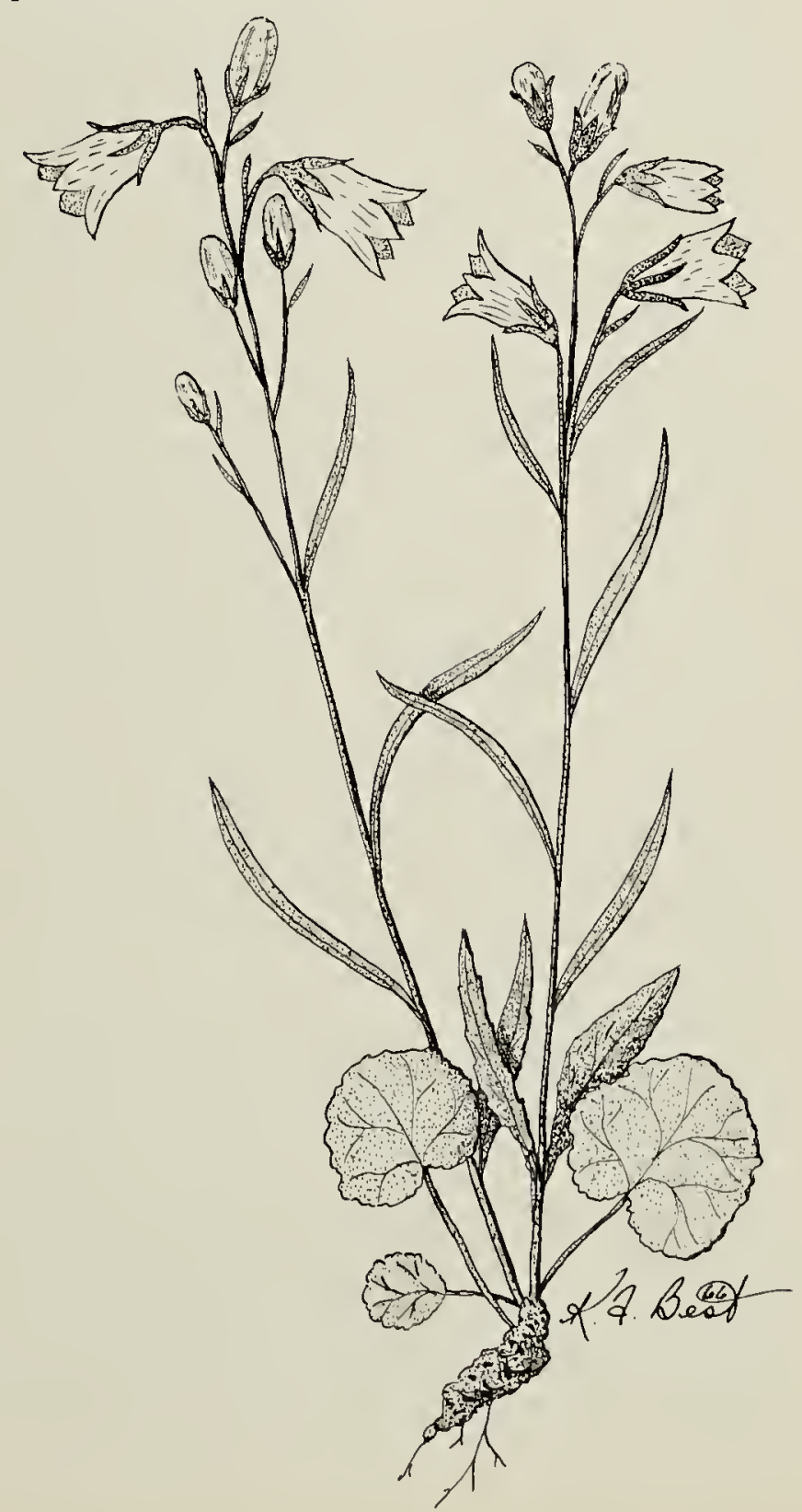

